OPEN ACCESS

Concentration Effects on the Spatial Interaction of Corrosion Pits Occurring on Zinc in Dilute Aqueous Sodium Chloride

To cite this article: N. Wint et al 2019 J. Electrochem. Soc. 166 C3028

View the article online for updates and enhancements. 


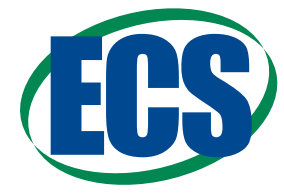

JeS Focus Issue on Advanced Techniques in Corrosion Science in Memory of Hugh Isaacs

\title{
Concentration Effects on the Spatial Interaction of Corrosion Pits Occurring on Zinc in Dilute Aqueous Sodium Chloride
}

\author{
N. Wint, ${ }^{\mathrm{z}}$ K. Khan, J. H. Sullivan, and H. N. McMurray* \\ Materials Research Centre, College of Engineering, Swansea University, Bay Campus, Crymlyn Burrow, Swansea SA1 \\ 8 EN, United Kingdom
}

\begin{abstract}
The scanning vibrating electrode technique is used to study the localized corrosion of unpolarized zinc in near-neutral aqueous sodium chloride electrolyte of varying concentration $[\mathrm{NaCl}]$. As $[\mathrm{NaCl}]$ is reduced from $1 \%(\mathrm{w} / \mathrm{v})$ to $0.0005 \%(\mathrm{w} / \mathrm{v})$ the morphology of attack changes from large, irregular, areas of anodic zinc dissolution and cathodic oxygen reduction, to a regular array of anodic pits set in an otherwise cathodic surface. In dilute electrolyte $([\mathrm{NaCl}]<0.01 \%)$ the total (area averaged) corrosion current density, $J,\left(\mathrm{~A} \cdot \mathrm{m}^{-2}\right)$, obtained from a numerical area integral of SVET anodic current density data, is shown to vary with approximately the square root of $[\mathrm{NaCl}]$. The number density of pits, $n\left(\mathrm{~m}^{-2}\right)$ is shown to decrease with increasing $[\mathrm{NaCl}]$. The mean individual pit current, $\overline{i_{p i t}},(A=J / n)$ varies with approximately the square root of [ $\left.\mathrm{NaCl}\right]$. A simple geometric analysis, based on a calculation of the radial dependence of electrical resistance exhibited by a hemispherical shell of electrolyte concentric with the pit, is used to explain the relationship between ohmic potential drop in the external solution, solution conductivity, and the radial distance away from an existing active pit.

(C) The Author(s) 2019. Published by ECS. This is an open access article distributed under the terms of the Creative Commons Attribution 4.0 License (CC BY, http://creativecommons.org/licenses/by/4.0/), which permits unrestricted reuse of the work in any medium, provided the original work is properly cited. [DOI: $10.1149 / 2.0051911$ jes]

(cc) BY
\end{abstract}

Manuscript submitted November 6, 2018; revised manuscript received January 14, 2019. Published January 24, 2019. This paper is part of the JES Focus Issue on Advanced Techniques in Corrosion Science in Memory of Hugh Isaacs.

Zinc provides sacrificial protection to a number of substrates and consequently enjoys widespread technological application. Pitting corrosion is observed on $\mathrm{Zn}$ in the presence of aggressive anions, such as chloride, ${ }^{1-12}$ but can also occur in very dilute environments, such as distilled water. ${ }^{4} \mathrm{Zn}$ is only passive over a very limited range of $\mathrm{pH}$ and consequently exhibits passivity breakdown in a wide range of electrolytes over a wide range of concentrations. Galvele concluded that: i) in unbuffered solution the pitting potential of $\mathrm{Zn}$ is close to the equilibrium potential for Eqaution 1 and ii) pitting starts as a result of local acidification of the metal surface. ${ }^{1}$ It has been shown elsewhere that repassivation of the $\mathrm{Zn}$ surface only occurs when $\mathrm{pH} \geq \mathrm{ca}$. 8.5. ${ }^{11}$

$$
\mathrm{Zn} \rightarrow \mathrm{Zn}^{2+}+2 e^{-}
$$

The surface film forming on $\mathrm{Zn}$ can be composed of $\mathrm{Zn}$ oxide, ${ }^{9}$ $\mathrm{Zn}$ hydroxide, ${ }^{6,8,10}$ or salts such as $\mathrm{Zn}$ hydroxychloride, which is the predominant component in the presence of $\mathrm{NaCl}^{6}$ The presence of aggressive anions (such as $\mathrm{Cl}^{-}$) can cause the breakdown of this film, and subsequent pit initiation is believed to occur as a result of film penetration, ${ }^{12-14}$ film breaking, ${ }^{15,16}$ or adsorption. ${ }^{6,17}$ The initiation of pitting corrosion on $\mathrm{Zn}$ in $\mathrm{NaCl}$ electrolytes has previously been proposed to occur through the adsorption of $\mathrm{Cl}^{-}$anions on the passive film. ${ }^{6}$ The applied electrical field needed to cause film breakdown is lowered at these sites of adsorption, ${ }^{4}$ and subsequently in the case of higher $\mathrm{NaCl}$ concentrations, the field required for passivation breakdown is lower, ${ }^{4}$ and the pitting potential reduced. ${ }^{6,11,12}$ Nevertheless, for sustained pit growth to occur, i.e. for a transition from metastable to stable pitting, the $\mathrm{pH}$ at the pit bottom must become low enough to prevent repassivation. ${ }^{18}$ This has been shown to require a minimum value of the product of pit anodic current density and pit depth, referred to as the pit stability product. ${ }^{19}$

It is generally accepted that local acidification within the pit occurs as a result of anodic metal dissolution (Equation 1) and the subsequent hydrolysis of hydrated metal cations. . $^{3-7,20}$

The first acid dissociation coefficient $\left(\mathrm{pKa}_{1}\right)$ associated with the hydrolysis of the $\mathrm{Zn}^{2+}$ hexaquocation (Equation 2), is $9 .^{21}$

$$
\left[\mathrm{Zn}\left(\mathrm{H}_{2} \mathrm{O}\right)_{6}\right]_{(a q)}^{2+} \leftrightarrow\left[\mathrm{Zn}\left(\mathrm{H}_{2} \mathrm{O}\right)_{5} \mathrm{OH}\right]_{(a q)}^{+}+H_{(a q)}^{+}
$$

It is therefore likely that any hydrolytic acidification occurring due to Equation 2 will be limited in dilute electrolyte. However, migration

\footnotetext{
*Electrochemical Society Member.
}

${ }^{\mathrm{z} E}$ E-mail: n.wint@swansea.ac.uk of $\mathrm{Cl}^{-}$anions to the pit anode will also produce a pit electrolyte richer in $\mathrm{Cl}^{-}$than the external electrolyte. In concentrated chloride solutions tetrahedral chloro-aqua complexes $\left(\mathrm{ZnCl}_{x} \mathrm{H}_{2} \mathrm{O}_{(4-x)}\right)$ may form. ${ }^{22-24}$ The reduction of $\mathrm{Zn}$ coordination number from 6 to 4 , reduces the $\mathrm{O}-\mathrm{H}$ bond strength and $\mathrm{ZnCl}_{x} \mathrm{H}_{2} \mathrm{O}_{(4-x)}$ solutions may become significantly more acidic $(\mathrm{pH} \sim 4)$ than those of dilute $\mathrm{Zn}^{2+}$ salts. ${ }^{25}$

The pitting of $\mathrm{Zn}$ has previously been studied using a 2-compartment cell (with a Zn electrode in each). One compartment (non-pitting) contains only a borate buffer solution whilst the other (the pitting compartment) also contains a varying concentration of chloride ions. ${ }^{8}$ In that work, the pitting corrosion current was estimated by measuring the current passing between the two cell compartments using a zero resistance ammeter. Pitting currents were found to become stable after $\sim 30$ minutes of electrolyte contact and to increase with chloride ion concentration $\left[\mathrm{Cl}^{-}\right]$according to $\log i_{\text {pit }}=$ const + $0.66 \log \left[\mathrm{Cl}^{-}\right]{ }^{8}$ The increase in current was ascribed to an increase in the number of pits, but no quantification of pit number density or individual pit currents was possible. ${ }^{8}$ Other authors have made qualitative arguments regarding how electrolyte conductivity influences the spatial distribution of corrosion features on $\mathrm{Zn} .{ }^{4,5}$ Thus it has been stated that, in the case that ionic conductivity is efficient (concentrated electrolyte), "anodes and cathodes can be physically separated, leading to a general attack". Whereas, in the case that ionic conductivity is poor (dilute electrolyte), "anodes and cathodes stay very close together". ${ }^{4}$ Here we will present a quantitative investigation of how electrolyte $(\mathrm{NaCl})$ concentration influences both the individual pit current and the number density of stable corrosion pits evolving on a $\mathrm{Zn}$ surface.

Various recent attempts have been made to model the spatial and temporal behavior of corrosion pits and how they interact due to ohmically produced potential gradients in the external electrolyte. ${ }^{26-28}$ Furthermore, a number of studies have been made into the nature and extent of the external potential gradient. Experimentally, the external potential drop resulting from current flowing to a disk electrode was found to be concentrated to the electrolyte near the disk. ${ }^{29}$ Similarly, an artificial pit electrode was used to show that the external potential drop became significant at high current values in the case of low electrolyte concentrations $(\sim 0.01 \mathrm{M} \mathrm{NaCl})$, and ion conductivity. ${ }^{30}$ An alternative approach has made use of computational modelling to show that the ohmic potential drop in solution causes 'shielding' in the region adjacent to a pit, within which pitting susceptibility is suppressed. ${ }^{26,27}$ However, this latter work assumed potentiostatic control and thus the presence of a remote cathode with the ability 
to supply an infinite current. ${ }^{27}$ Elsewhere the typical ohmic potential drop in solution near a pit has been quoted as $75-100 \mathrm{mV}^{31,32}$

Here we show that unpolarized pure $\mathrm{Zn}$ is a particularly suitable system for the experimental investigation of how electrolyte concentration affects the spatial behavior of pitting corrosion under nearneutral conditions. This is largely due to the limited range of $\mathrm{pH}$ over which $\mathrm{Zn}$ exhibits passive behavior and its consequent tendency to pit spontaneously over a wide range of electrolyte concentrations. ${ }^{33,34}$ However, the same ease of passivity breakdown also limits the influence that metallurgical features and pre-existing defects have on the location at which pits may occur. This tends to maximize the influence of electrolyte concentration (and hence conductivity) on pit-pit spatial interaction. Isaacs has previously demonstrated the feasibility of using the scanning reference electrode technique (SRET) to monitor the spatial and temporal behavior of pitting corrosion on 304 stainless steel..$^{35}$ In the work to be described here we use a derivative of the SRET, the scanning vibrating electrode technique (SVET), also pioneered for corrosion studies by Isaacs, ${ }^{36}$ to study the pitting of $\mathrm{Zn}$. In so doing it has been our aim to better determine the role that electrolyte conductivity $(K)$, and ohmic potential gradients in solution external to the pit, have on the distance over which one stable pit can effectively suppress the stabilization of further pitting events.

\section{Experimental}

Materials.-Commercial purity $\mathrm{Zn}$ foil of $1 \mathrm{~mm}$ thickness and $99.9+\%$ purity was obtained from Goodfellow Ltd, UK. In all cases, coupons were mounted flat in non-conductive Buehler's Black Phenolic Premold using a Struers mould press. The samples were then polished to a uniform $1 \mu \mathrm{m}$ finish using diamond slurry, washed with acetone and dried. Extruded PTFE tape (type 5490 HD supplied by $3 \mathrm{M})$ was used to expose an area in the center.

$\mathrm{NaCl}$ and all other chemicals were obtained from Sigma Aldrich Chemical Co. and were of analytical grade purity. The $[\mathrm{NaCl}]$ values used are shown in Table I.

Methods.-The SVET makes use of the ionic current flux and the resultant ohmically generated potential field that exists within the electrolyte in which a corroding sample is immersed. ${ }^{37-41}$ The vibrating SVET microtip detects an alternating potential at the vibration frequency, this value being proportional to the electric field strength or potential gradient in the direction of vibration. ${ }^{37-41}$

A schematic of the SVET apparatus is shown in Figure 1a. The microtip used consists of a platinum microelectrode which is enclosed in

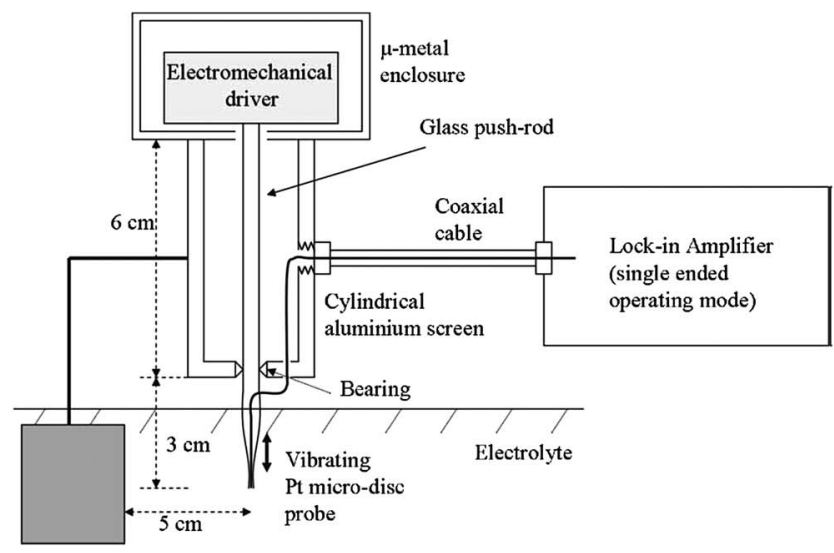

Large, low impedance $\mathrm{AgCl}$ reference electrode (instrument earth)

(a)

\section{Table I. NaCl electrolyte concentration values used during} experimentation.

$\mathrm{NaCl}$ Concentration \% (w/v)

$$
\begin{gathered}
0.0005 \\
0.001 \\
0.005 \\
0.01 \\
0.05 \\
0.1 \\
1.0
\end{gathered}
$$

a glass sheath. The microelectrode had a diameter of $125 \mu \mathrm{m}$ and the total tip diameter was $250 \mu \mathrm{m}$. An electromagnetic driver provided a probe vibration frequency of $140 \mathrm{~Hz}$ via a pushrod. The amplitude of probe vibration was $25 \mu \mathrm{m}$. Electromagnetic flux leakage was minimized by encasing the electromagnetic driver in a $\mu$ metal enclosure. Similarly, an aluminum cylinder was used to enclose the pushrod and the wiring attached to the microelectrode. Tip vibration was constrained to the perpendicular vibration using a bearing. A chloridized low impedance silver chloride reference electrode of dimensions $2.5 \mathrm{~cm} \times 2.5 \mathrm{~cm}$ was attached to this cylinder in such a way that the distance between the probe and reference electrode was ca. $5 \mathrm{~cm}$.

Three linear bearings, driven by stepper motors (Time and Precision Ltd) were used to move the SVET probe assembly, and a Perkin Elmer 7265 lock-in amplifier was used to detect the SVET voltage signal. Measurement of the peak-to-peak SVET probe vibration amplitude ( $a_{p \mathrm{p}}=30+/-5$ micron), was obtained in air using a stroboscope in conjunction with a traveling microscope.

By Ohm's law, the peak-to-peak SVET voltage signal $V_{p p}$ is related to current flux density along the axis of probe vibration normal to the sample surface $\left(j_{z}\right)$ by $V_{p p}=j_{z}\left(a_{p p} / K\right)$, such that a quantity $a_{p p} / K$ may be defined as the SVET calibration factor. ${ }^{37-41}$ SVET calibration was checked galvanostatically in aqueous $\mathrm{NaCl}$ electrolyte of different concentrations using a specially devised two-compartment cell. A calibration procedure was carried out to obtain values of current flux density along the axis of probe vibration $\left(j_{z}\right)$ from the SVET voltage signal and the procedure has been described in detail elsewhere. ${ }^{37-41}$ The apparatus required to complete the calibration can be seen in Figure $1 \mathrm{~b}$ and includes a two compartment cell, where one compartment consists of a nylon beaker containing a $1 \mathrm{~cm}^{2}$ platinum electrode, and the other consisted of a $6 \mathrm{dm}^{3}$ tank filled with the experimental

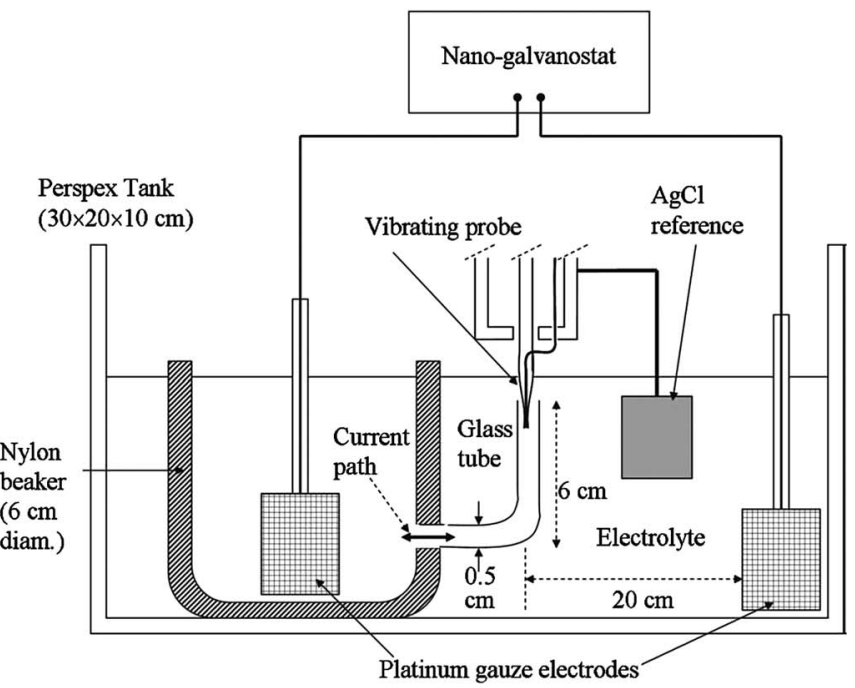

(b)

Figure 1. Schematic representations of a.) the SVET probe/vibrator assembly and b.) the calibration cell. Reproduced with permission. ${ }^{35}$ 
electrolyte. The latter compartment also contained a $1 \mathrm{~cm}^{2}$ platinum electrode, the distance between the electrodes being $10-20 \mathrm{~cm}$. A $6 \mathrm{~cm}$ long, vertically orientated glass tube, with a diameter of $0.5 \mathrm{~cm}$, linked the two compartments. The tip was placed in this tube, ensuring that the silver chloride electrode was immersed in the electrolyte. The tip was immersed at such a depth that the current flux density was assumed to be constant across its diameter and current flux aligned vertically (parallel with axis of tube and direction of tip vibration). Known current values were passed through the tube using a battery powered galvanostat and the resultant SVET $V_{p p}$ signal was recorded. The plots generated were subsequently used to obtain a calibration factor which allowed the conversion of SVET $V_{p p}$ signals to normal current density $\left(j_{z}\right)$ values.

Following calibration, the mounted samples were securely attached to a Perspex stage within the SVET apparatus using nylon screws to ensure stability. The $\mathrm{Zn}$ samples were completely immersed in a range of $\mathrm{NaCl}(\mathrm{aq})$ electrolyte concentrations $[\mathrm{NaCl}]$ from $0.0005 \%(\mathrm{w} / \mathrm{v})$ up to $1 \%(\mathrm{w} / \mathrm{v})($ all concentrations (in $\% \mathrm{w} / \mathrm{v}$ ) will be given as $\%$ from this point forward). SVET scans were carried out immediately following immersion and every 30 minutes thereafter for a total of 5 scans per sample. Individual scans took approximately 15 minutes. The SVET probe was scanned at a fixed height of $100 \mu \mathrm{m}$ normal to the $\mathrm{Zn}$ surface and the electrolyte was maintained unstirred at a nominal temperature of $20^{\circ} \mathrm{C}$. All SVET experiments were repeated a total of 3 times at each experimental value of $[\mathrm{NaCl}]$.

When considering SVET data it should be borne in mind that the SVET will efficiently detect only those localized corrosion currents arising from anodic and cathodic sites which are separated by distances greater than the scan height $(100 \mu \mathrm{m})$. When the spacing is less than the scan height, current flux lines (Figure 2) will tend not to intersect the plane of scan and will consequently be detected inefficiently or not at all. ${ }^{37,41}$ Furthermore, the theoretical width at half maximum $(\mathrm{whm})$ of the SVET response peak for a point current source is $1.53 z$ (where $z$ is the probe height). ${ }^{38}$ Peak broadening can also occur due to the finite width of the electrically sensitive portion of the SVET probe tip. It has previously been shown that the whm for the SVET used here is $\sim 260 \mu \mathrm{m}$ when $z=100 \mu \mathrm{m}^{41}$

SVET derived normal current density $\left(j_{z}\right)$ data were plotted using Surfer 8 (Golden Software). The number of active pits present on each sample and hence the number density of pits $\left(\mathrm{n} / \mathrm{m}^{2}\right)$ were determined by counting the number of well-defined anodic $j_{z}$ peaks in the corresponding SVET map by eye. The total anodic current $\left(I_{a(t)}\right)$ and area-averaged total anodic current density $\left(J_{a(t)}\right)$ associated with corrosion was obtained by numerically integrating all the positive $j_{z}$ values present in each scan using Equation 3

$$
I_{a t}=A \cdot J_{a(t)}=\int_{0}^{X} \int_{0}^{Y}\left[j_{z(x, y, t)}>0\right] d x d y
$$

where $A$ is sample area and $X$ and $Y$ are the length and width of the SVET scan respectively. The accuracy with which Equation 3 might be expected to estimate $J_{a(t)}$ will be discussed further below.

Optical micrographs and depth profiles were obtained using a Keyence VHX-700F digital microscope. The microscope can be used to take multiple images between upper and lower focal lengths. A Depth from Defocus method was then used to calculate 3D depth information from the defocusing of $2 \mathrm{D}$ images.

\section{Results}

The electrolyte concentration dependent pitting of zinc.-On immersion in aqueous $\mathrm{NaCl}$ electrolyte, $\mathrm{Zn}$ undergoes corrosive attack with anodic dissolution of $\mathrm{Zn}$ (via Equation 1) and cathodic oxygen reduction (ORR) which occurs via Equation 4 (4 electron pathway), in the case that potentials are low enough to produce a bare surface, or via Equation 5 ( 2 electron pathway) in the case that the zinc surface is covered with zinc hydr(oxide). ${ }^{42} \mathrm{H}_{2} \mathrm{O}_{2}$ may then become oxidized via Equation 6 meaning that 4 electron and 2 electron pathways can

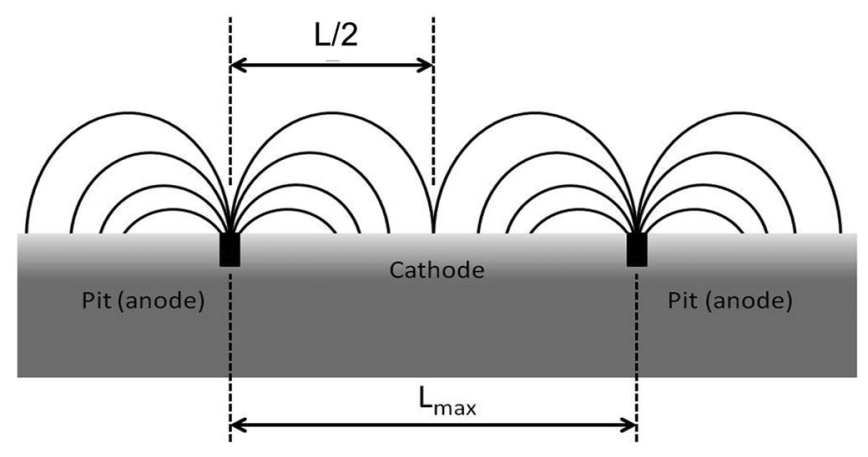

Figure 2. Schematic of pit corrosion cell on pure zinc freely corroding in $\mathrm{NaCl}(\mathrm{aq})$.

occur alone or in combination. ${ }^{42}$

$$
\begin{gathered}
\mathrm{O}_{2}+2 \mathrm{H}_{2} \mathrm{O}+4 e^{-} \rightarrow 4 \mathrm{OH}^{-} \\
\mathrm{O}_{2}+\mathrm{H}_{2} \mathrm{O}+2 e^{-} \rightarrow \mathrm{HO}_{2}^{-}+\mathrm{OH}^{-} \\
\mathrm{HO}_{2}^{-}+\mathrm{H}_{2} \mathrm{O}+2 e^{-} \rightarrow 3 \mathrm{OH}^{-}
\end{gathered}
$$

Figure 3 shows optical images of the localized corrosion observed on pure $\mathrm{Zn}$ surfaces after 2 hours of immersion in various concentrations of $\mathrm{NaCl}(\mathrm{aq})$. In the case of the highest $[\mathrm{NaCl}],(1 \%)$ few localized corrosion features can be observed and corrosion appears to be more generalized in nature. For lower $[\mathrm{NaCl}]$, circular features, typical of pitting corrosion, are evenly distributed across the surface. Unexpectedly, the number of pits increases with decreasing $[\mathrm{NaCl}]$. Figure 4 shows an optical image of another sample which had been immersed in $0.001 \% \mathrm{NaCl}$ for 2 hours. The size of the pits is largely uniform and they are approximately $400 \mu \mathrm{m}$ in diameter. Each pit appears to be surrounded by a radial deposit of white corrosion product.

When $\mathrm{Zn}$ samples were allowed to continue corroding over longer periods (up to 1 week), both the number concentration of pits $(n)$ and the location of the pits, were not observed to change with time. However, the pit depth was found to increase with time. Figure 5a

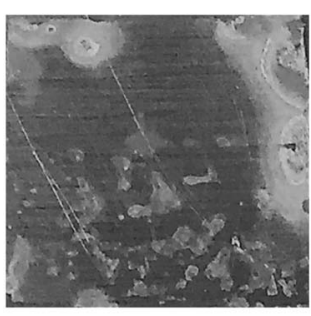

$1 \% \mathrm{NaCl}$

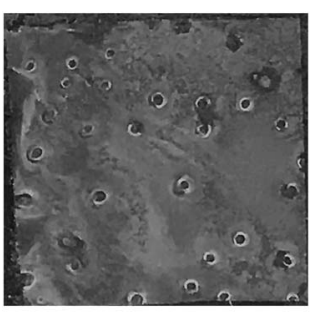

$0.01 \% \mathrm{NaCl}$

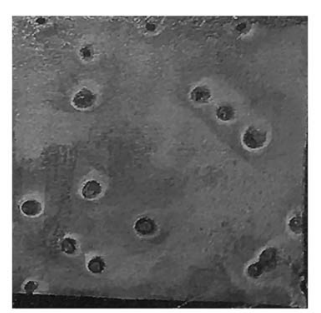

$0.1 \% \mathrm{NaCl}$
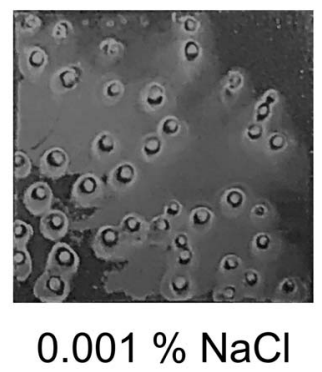

Figure 3. Optical images of pure zinc samples after 2 hours of immersion in various concentrations of $\mathrm{NaCl}(\mathrm{aq})$. 

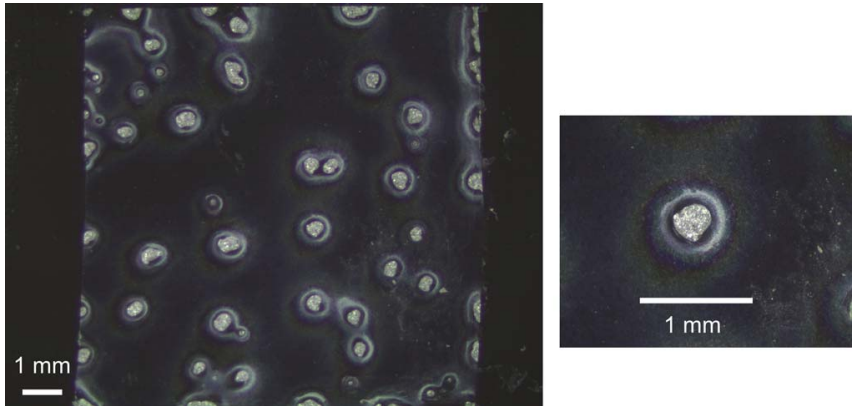

Figure 4. Optical images of a pure zinc sample after 2 hours of immersion in $0.001 \%(\mathrm{w} / \mathrm{v}) \mathrm{NaCl}(\mathrm{aq})$.

shows the topography of the pitted Zn sample after 1 week in $0.001 \%$ $\mathrm{NaCl}$, as measured using a Keyence VHX-700F digital microscope. The depth profile of an individual pit, measured along the axis X-X' (Figure 5a), is shown in Figure 5b. The internal pit surface is smoothly contoured and shows little or no evidence of crystallographic etching. The shape of the pit is close to being hemispherical but is somewhat flattened or dish shaped. The appearance of the pit and the pit profile is consistent with the growth of stable pits occurring under substantially mass transport (as opposed to surface) control. ${ }^{20}$

The total charge, $Q$, emitted by an anodic pit over the experimental time period, $t$, can be calculated via Faraday's law using Equation 7

$$
Q=\int_{0}^{t} i_{p i t} d t=\frac{2 F m}{M}
$$

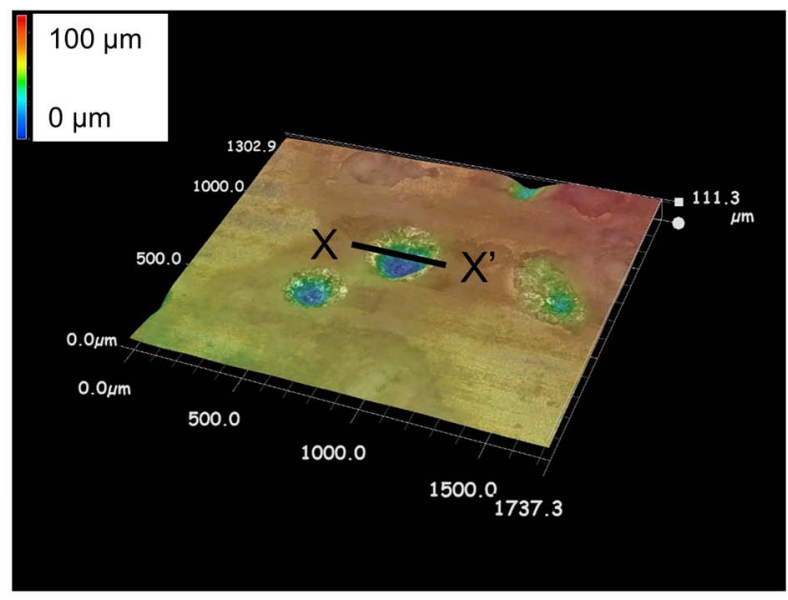

a)

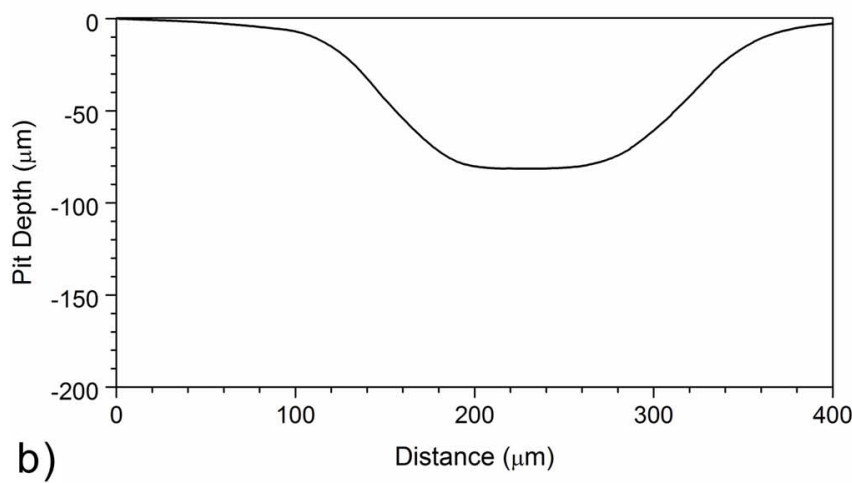

Figure 5. a.) A height color map showing the surface topography of a pitted zinc surface taken after 7 days of immersion in $0.001 \%(\mathrm{w} / \mathrm{v}) \mathrm{NaCl}(\mathrm{aq})$ electrolyte b.) depth profile of an individual pit, measured along axis $\mathrm{X}-\mathrm{X}$, in a.) where $m$ is the mass loss, $M$ is the atomic weight of zinc $(65.38 \mathrm{Da})$, 2 is the valence of metal ions and $F$ is the Faraday constant. The volume of the pit shown in Figure $5 \mathrm{~b}$ was estimated to be $(1.7 \pm$ $0.4) \times 10^{-6} \mathrm{~cm}^{3}$ by numerical integration of the depth profile data. Using the known density of zinc $\left(7.14 \mathrm{~g} \mathrm{ml}^{-1}\right)$ the corresponding mass loss was calculated to be $(12 \pm 3) \mu \mathrm{g}$ and Equation 7 was used to obtain a pit current (time-averaged over the 1 week immersion period $)$ of $(59 \pm 15) \mathrm{nA}$. It should be borne in mind that this value is time averaged and does not consider how the pit current changes with time.

SVET measurements.-Figure 6 shows a series of typical SVETderived $j_{z}$ distribution maps measured above the surface of $\mathrm{Zn}$ freely corroding in electrolyte containing $[\mathrm{NaCl}]$ between $1 \%$ and $0.001 \%$. In each case the $j_{z}$ data was obtained between 90 and 108 minutes following electrolyte immersion. The $j_{z}$ data are presented in a false color format with anodic $j_{z}$ shown in red and cathodic $j_{z}$ in blue. At the highest experimental $[\mathrm{NaCl}]$ of $1 \%$ the corrosion picture, although localized, does not strongly resemble pitting. The anodic sites are irregular and broad (up to $2 \mathrm{~mm}$ diameter). Localization occurs near the edge of the bare sample area i.e. at the border. This could be the result of differential aeration arising from the $\left(\mathrm{O}_{2}\right.$ impermeable) tape or even crevice corrosion (beneath the tape). Whatever the reason, zinc corrosion within $1 \% \mathrm{NaCl}$, although localized, does not strongly resemble pitting corrosion. Conversely, for $[\mathrm{NaCl}]$ between $0.1 \%$ and $0.001 \%$ the corrosion picture is one of a collection of small, pit-like, anodic sites, all of fairly uniform intensity, distributed over an otherwise cathodic surface. As the experimental $[\mathrm{NaCl}]$ is increased from $0.001 \%$ to $0.1 \%$ the maximum value of anodic $j_{z}$ increases monotonically from $0 \cdot 35 \mathrm{~A} \cdot \mathrm{m}^{-2}$ to $5 \mathrm{~A} \cdot \mathrm{m}^{-2}$ Conversely, over the same range of $[\mathrm{NaCl}]$ the number of pits per sample falls monotonically from 45 to 16 .

The experimental $j_{z}$ distributions measured above corroding $\mathrm{Zn}$ were found to remain substantially unchanging over the 2 hour duration of the SVET experiment. Figure 7 shows SVET derived $j_{z}$ distribution maps obtained over $\mathrm{Zn}$ freely corroding in $0.001 \% \mathrm{NaCl}$ at times between 1 and 2 hours following electrolyte immersion. It may be seen that the number, location and intensity of anodic $j_{z}$ (pit) features remains approximately constant throughout. The invariance of $j_{z}$ values with electrolyte immersion time was generally observed, at all $[\mathrm{NaCl}]$, and this was reflected in the area averaged total anodic current density $\left(J_{a(t)}\right)$ values obtained from the $j_{z}$ distribution maps using Equation 3. Figure 8 shows $J_{a(t)}$ values obtained plotted as a function of immersion time for various values of $[\mathrm{NaCl}]$ between $1 \%$ and $0.001 \%$. At this point it should be borne in mind that $J_{a(t)}$ is a hypothetical quantity, obtained by dividing the total anodic current integral (Equation 3) by the total area. It may be seen that $J_{a(t)}$ remains substantially independent of immersion time in all cases. However, the time independent $J_{a(t)}$ value increases monotonically with increasing $[\mathrm{NaCl}]$.

The anodic $j_{z}$ peaks in Figure 7 exhibit a width at half maximum (whm) of $\sim 300 \mu \mathrm{m}$ which is greater than the instrumental whm $(\sim 250 \mu \mathrm{m})$. Consequently, it would seem that the localized anodic (pit) features visible in the $j_{z}$ maps are generally larger than point current sources with the implication that their physical shape and size can, to some extent, be determined by SVET. On this basis, the shape of the $j_{z}$ distribution measured over individual pits was determined at different values of $[\mathrm{NaCl}]$. The effect of varying $[\mathrm{NaCl}]$ is perhaps most clearly visualized in the $j_{z}$ vs. distance line plots, Figure 9a and Figure 9b, which show the $j_{z}$ distribution measured along the axes $\mathrm{X}-\mathrm{X}^{\prime}$ and $\mathrm{Y}-\mathrm{Y}^{\prime}$ in Figure 9c and Figure 9d respectively. In the case of $[\mathrm{NaCl}]=0.01 \%$, the anodic $j_{z}$ distribution takes the form of a simple peak with a maximum value of $\sim 0.55 \mathrm{~A} \cdot \mathrm{m}^{-2}$. In contrast, at $[\mathrm{NaCl}]=$ $0.001 \%$, the center of the peak is suppressed and two anodic $j_{z}$ maxima are observed at the pit perimeter. These findings are consistent with anodic current flux lines becoming ohmically truncated in the case that electrolytes of lower $[\mathrm{NaCl}]$ are used, thus forcing anodic flux to the perimeter of the pit. The same phenomenon was observed by Isaacs when using SVET to measure the current distribution above 
$j_{z}\left(\mathrm{~A} \cdot \mathrm{m}^{-2}\right)$
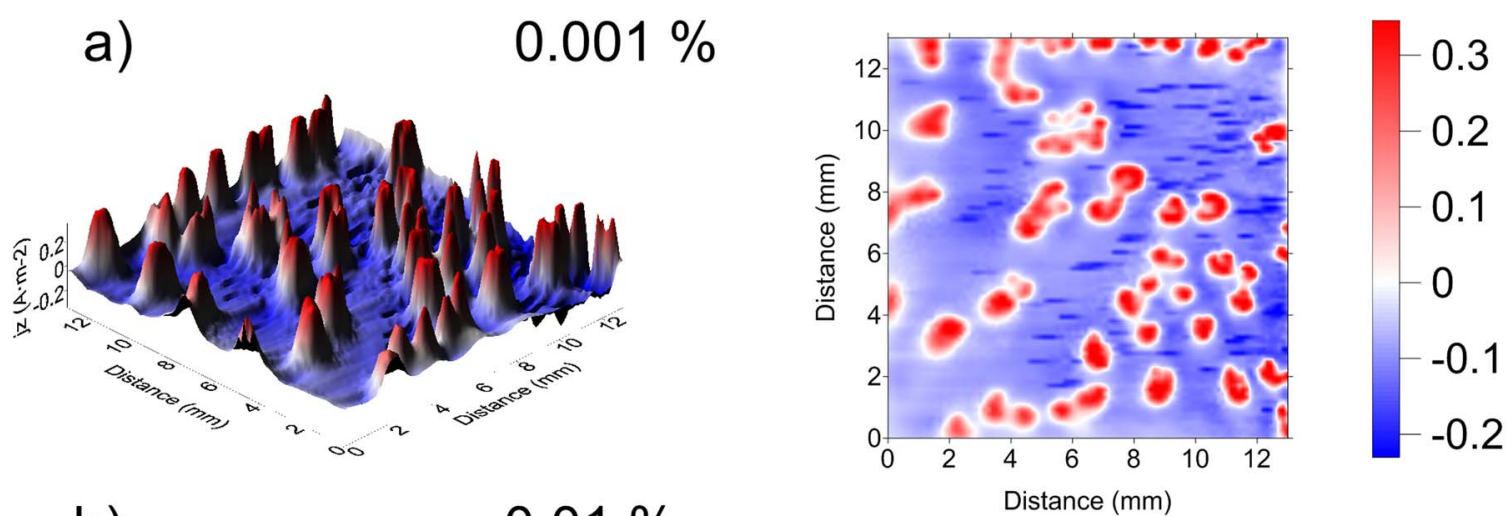

b)

$0.01 \%$
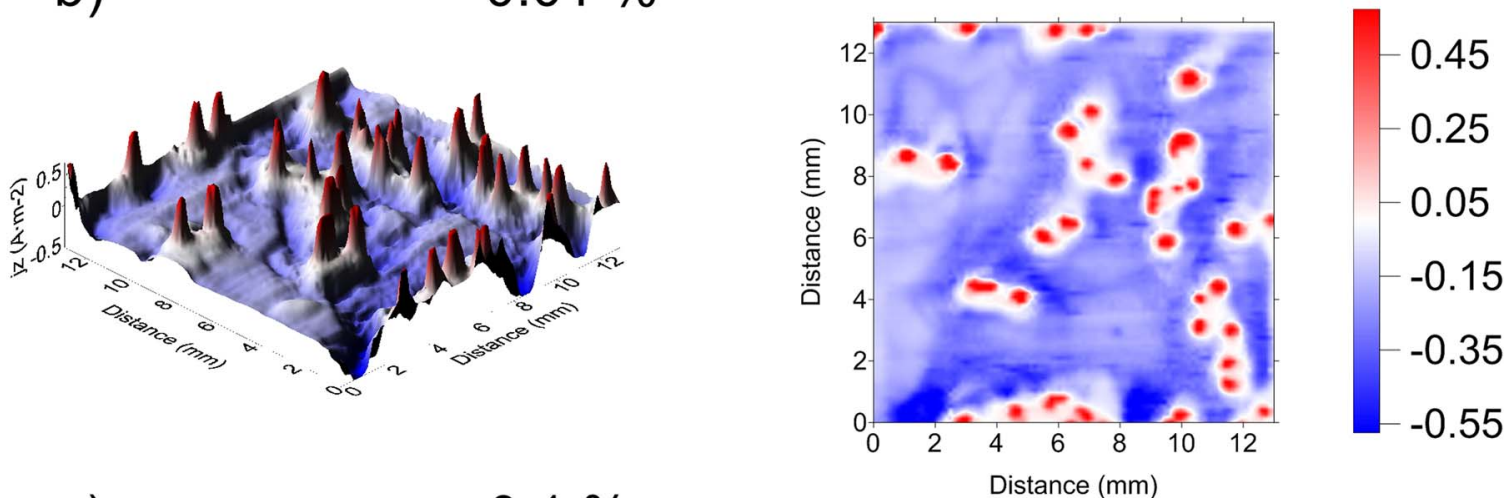

c)

$0.1 \%$
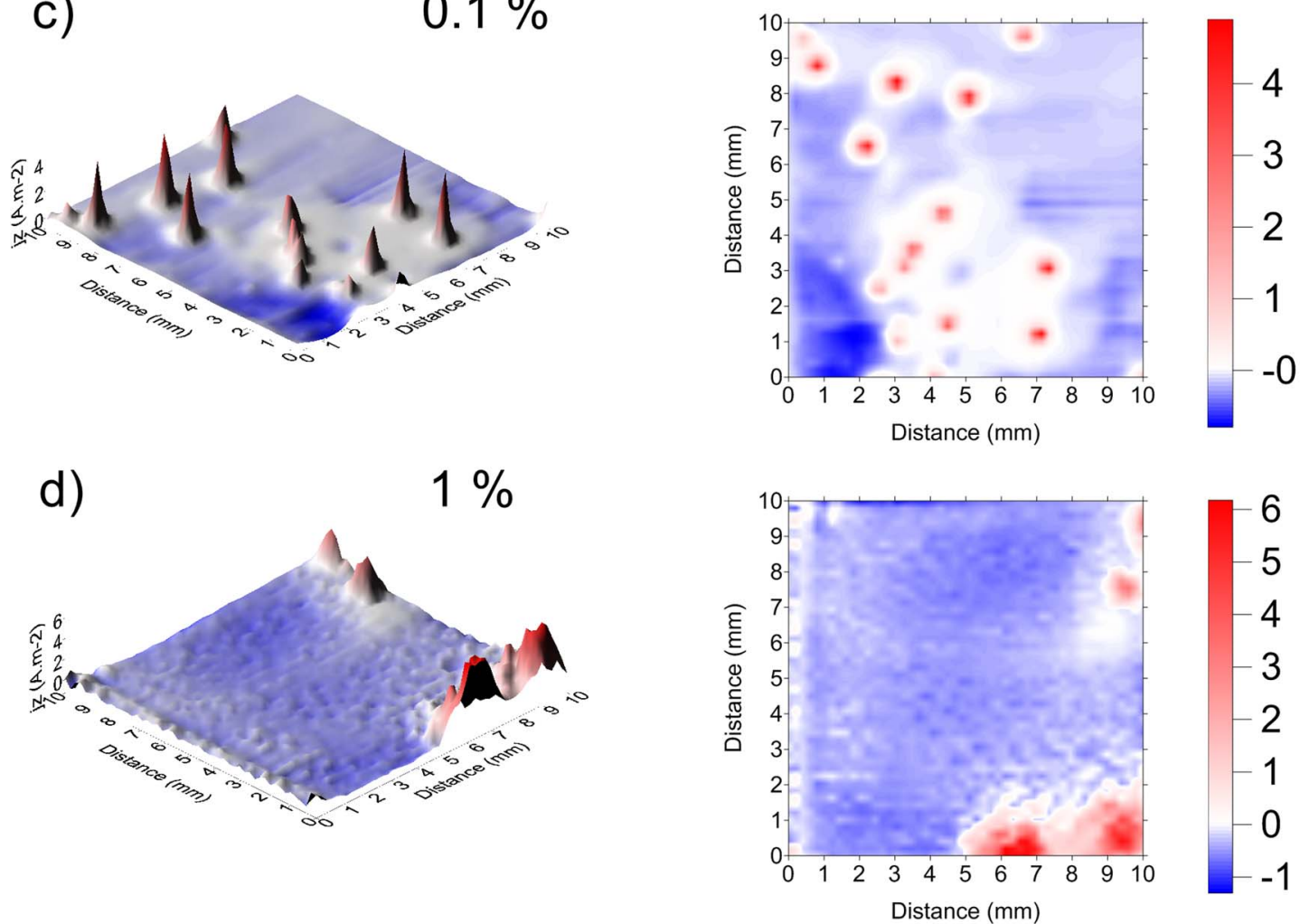

Figure 6. SVET derived surface maps showing the distribution of normal current density $j_{z}$ above a zinc sample freely corroding after 2 hours of immersion in near neutral $\mathrm{NaCl}$ of varying concentrations a.) $0.001 \%(\mathrm{w} / \mathrm{v})$, b.) $0.01 \%(\mathrm{w} / \mathrm{v}), \mathrm{c}) 0.1 \%.(\mathrm{w} / \mathrm{v})$ and d.) $1 \%(\mathrm{w} / \mathrm{v})$. 


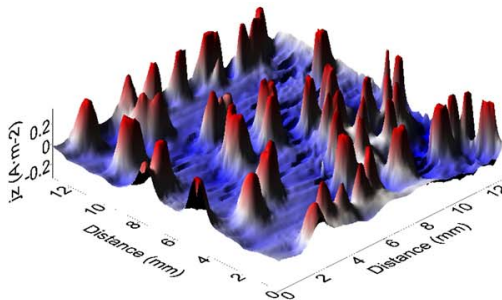

60 mins

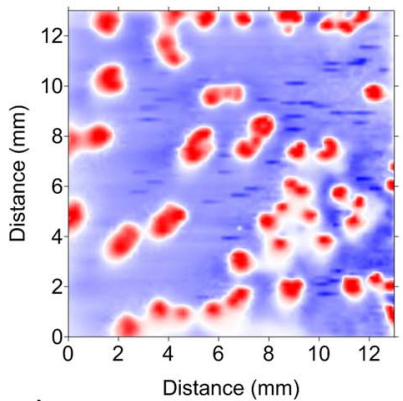

a)

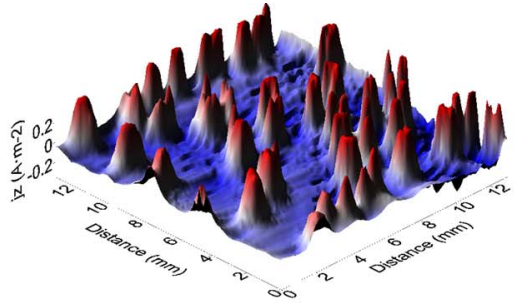

90 mins

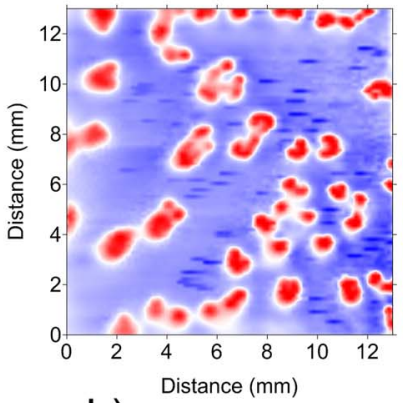

b)

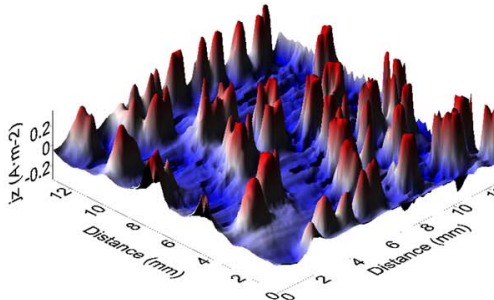

0.3

0.2

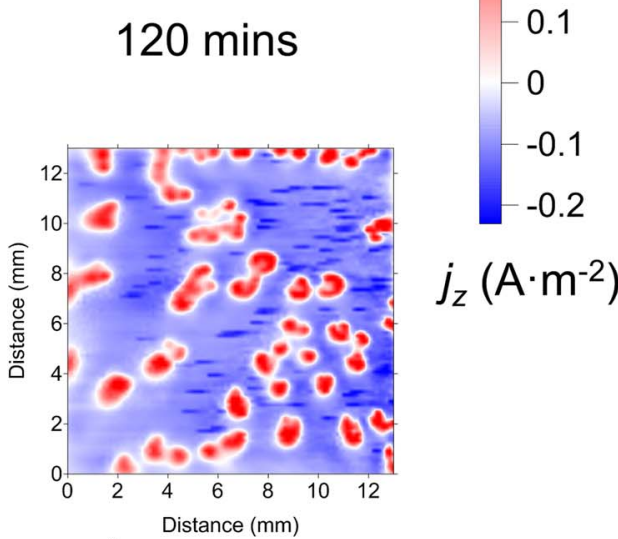

c)

Figure 7. SVET derived surface maps showing the distribution of normal current density $j_{z}$ above a zinc sample freely corroding in near neutral $0.001 \%$ (w/v) $\mathrm{NaCl}$ (aq) after varying times of immersion a.) 60 minutes, b.) 90 minutes, c.) 120 minutes.

an isopotential disc in an insulating plane. ${ }^{36}$ However, the lateral resolution of the SVET is not sufficient for an accurate measurement of pit radii and, when required, these have been obtained directly from photographs of the corroded surface within this work.

In contrast with the highly localized anodic $j_{z}$ features seen in Figure 6 and Figure 7, the cathodic $j_{z}$ distributions tend to be much more uniform over the sample surface (outside the pits) and show no obvious tendency to become localized (or concentrated) proximal to the anodic $j_{z}$ features as $[\mathrm{NaCl}]$ decreases. This is, at first sight, counterintuitive as the ohmic potential drop associated with anode-cathode current loops in solution would cause the activation overpotential for $\mathrm{O}_{2}$ reduction to decrease with radial distance from the anodic feature. However, it should be remembered that $\mathrm{O}_{2}$ is very poorly soluble in aqueous $\mathrm{NaCl}$ (the dissolved oxygen concentration in bulk solution was assumed to be $2.8 \times 10^{-4} \mathrm{~mol} \cdot \mathrm{dm}^{-3}$, the equilibrium concentration for air saturated water $)^{43}$ and for rapidly corroding systems such as that studied here, quickly becomes diffusion controlled. The mass transfer overpotential associated with ORR will depend only on $\mathrm{O}_{2}$ concentration and the thickness of the Nernst diffusion layer. Consequently, local mass transport limitation of cathodic $\mathrm{O}_{2}$ reduction currents will tend to have a (to some extent) uniformizing effect on cathodic $j_{z}$ distribution. Cathodic current density values $j_{z}$ are relatively low and fairly uniform. Consequently, any systematic underestimation of the anodic $j_{z}$ integral (Equation 3), arising as a result of imperfect lateral resolution of anodic and cathodic $j_{z}$ contributions, is predicted to be small.

The probability of pit stabilization on $\mathrm{Zn}$ has been shown to become lowered when significant electrolyte convection is present. ${ }^{5} \mathrm{~A}$ question therefore arises as to whether or not the lateral movement of the SVET probe, together with its vertical vibration, might perturb the patterns of pitting corrosion in measuring them. In order to make some estimate of any such possible effect, the visual appearance of the corroded Zn surfaces at the end of each SVET experiment was compared to that of samples which were optically examined only at the end of a period of electrolyte immersion without SVET measurement. In all cases, the number density, size and distribution of pits were found to be entirely similar at any given value of $[\mathrm{NaCl}]$. It therefore seems unlikely that probe movement, and any resulting increase in electrolyte convention, exerted a significantly perturbing effect in this instance.

\section{Discussion}

Accuracy in SVET.-The extent to which SVET derived data can be used in a quantitative manner was considered prior to any further analysis. SVET will obviously be unable to detect any electrochemical activity in the case that the resultant ionic flux is consumed within the pit cavity and does not cross the plane of scan, as shown schematically in Figure 10a. This would become problematic if (for example) hydrogen evolution made a significant contribution to the overall cathodic activity. However, hydrogen evolution in the pits was not observed in any of our experiments. Furthermore, in any homogeneous reaction involving $\mathrm{Zn}^{2+}$ cations (such as Equation 2) charge will actually be conserved so that SVET detection of anodic current will not be affected when the pit anode is coupled to a cathode which lies external to the pit (such as will be the case when cathodic oxygen reduction occurring on the external sample surface is the principal source of cathodic current).

It has previously been shown that the fraction of $I$ detected by the integration of $j_{z}$ (Equation 3) over the area concentric with a point current source $(I)$ set in an insulating plain is greater than $90 \%$ in the case that the point current source lies at a distance $\geq 9 z$ within the $x$ and $y$ integration limits. ${ }^{44}$ When external polarization is absent, for example for a metal surface undergoing pitting corrosion at open circuit, the efficiency will depend on the spacing of the anodic and cathodic sites. Whilst each pit can be thought of as a point anode, the cathodic reaction, which is assumed to be ORR, will cover the surrounding regions. The integral of $j_{z}$ will subsequently underestimate the value of $I$ when the current flux loop between the anode and cathode forms below $z$ and does not cross the plane of detection. One consequence of the relative uniformity of the cathodic current observed in Figure 6 is that the anode-cathode spacing is typically greater than $z$, with the implication that SVET will operate with a relatively high current detection efficiency. ${ }^{44,45}$ 


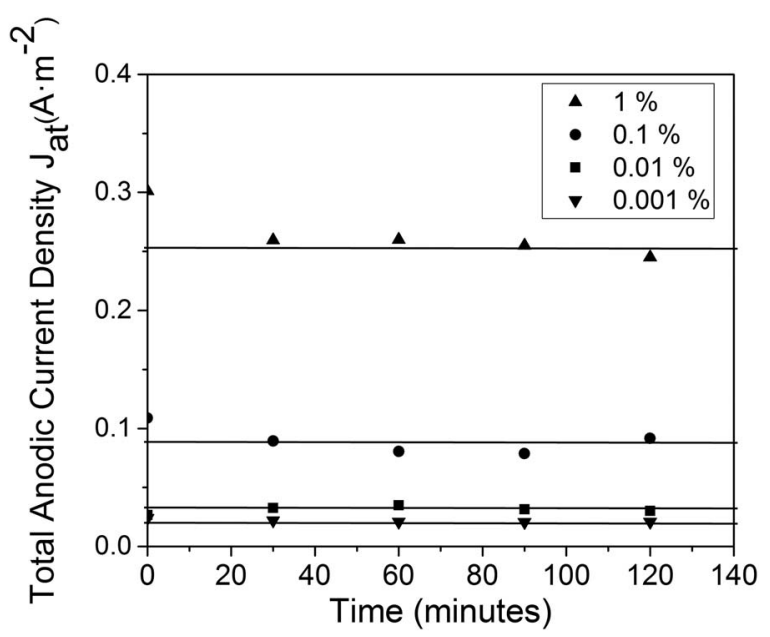

Figure 8. SVET derived total anodic current density $\left(J_{a(t)}\right)$ as a function of time zinc sample freely corroding after 2 hours of immersion in near neutral $\mathrm{NaCl}$ of varying concentrations.

On the basis of the above, values of $J_{a(t)}$ associated with corrosion occurring at each $[\mathrm{NaCl}]$ might reasonably be obtained using Equation 3 provided the $S$ VET calibration is accurate. It has previously been pointed out that estimates of current density can give rise to large errors when the SVET is used in a dilute solution. ${ }^{46,47}$ These errors arise from deviation from Ohm's law, caused in turn by a non-uniform ion distribution stemming from localized electrochemical reactions at the specimen surface. ${ }^{46}$ However, the experimental work on which these findings were based involved SVET measurement made over polarized platinum surfaces immersed in $\mathrm{NaCl}$. In the absence of a facile redox couple, electron transfer at the platinum electrode would take place via water electrolysis (the oxidation or reduction of water) ${ }^{46}$ The observed decrease in ohmic potential gradient in that work is then a consequence of the production of $\mathrm{H}^{+}$and $\mathrm{OH}^{-}$ions, which have significantly higher mobility values than $\mathrm{Na}^{+}$and $\mathrm{Cl}^{-}$as a consequence of their involvement in the Grotthuss mechanism of ionic conduction. ${ }^{48}$

In the present work, it is the accuracy of anodic current density estimates which are of the greatest importance, because it is the anodic current integrals (Equation 3) which are used during analysis of the through-solution pit interaction. In comparison to work completed on platinum, ${ }^{46}$ under the experimental conditions used here, significant levels of anodic water electrolysis are not predicted to occur. The diffusion coefficients of $\mathrm{Zn}^{2+}, \mathrm{Na}^{+}$and $\mathrm{H}_{3} \mathrm{O}^{+}$(hydrated $\mathrm{H}^{+}$) in water at $298.13^{\circ} \mathrm{K}$ are $7.03 \times 10^{-10} \mathrm{~m}^{2} \cdot \mathrm{s}^{-1}, 13.34 \times 10^{-10} \mathrm{~m}^{2} \cdot \mathrm{s}^{-1}$ and $93.11 \times$ $10^{-10} \mathrm{~m}^{2} \cdot \mathrm{s}^{-1}$ respectively. ${ }^{49}$ The Einstein diffusion equation is given by Equation 8, where $D$ is the diffusion coefficient, $\mu$ is the ionic mobility, $k$ is the Boltzmann's constant $\left(1.38 \times 10^{-23} \mathrm{~m}^{2} \cdot \mathrm{kg} \cdot \mathrm{s}^{-1} \cdot \mathrm{K}^{-1}\right)$, $T$ is the Temperature and $q$ is the charge on the relevant ion. Thus the value of $\mu$ (which is proportional to $D . q$ ) for the $\mathrm{Zn}^{2+}$ hexaquocation $\left(\left[\mathrm{Zn}\left(\mathrm{H}_{2} \mathrm{O}\right)_{6}\right]^{2+}\right.$ is similar to that of $\left[\mathrm{Na}\left(\mathrm{H}_{2} \mathrm{O}\right)_{6}\right]^{+}$. The value of $\mu$ for $\mathrm{H}_{3} \mathrm{O}^{+}$is 5-6 times greater than for either $\mathrm{Na}^{+}$or $\mathrm{Zn}^{2+}$.

$$
D=\frac{\mu k T}{q}
$$

However, $\mathrm{pKa} \mathrm{K}_{1}$ for $\left[\mathrm{Zn}\left(\mathrm{H}_{2} \mathrm{O}\right)_{6}\right]^{2+}$ is $\sim 9^{21}$ implying that significant release of $\mathrm{H}^{+}$through cation hydrolysis is not predicted to occur.

On the basis of the preceding argument, it is unlikely that large systematic errors in SVET calibration arise due to the localized electrochemical reactions associated with anodic $\mathrm{Zn}$ dissolution when
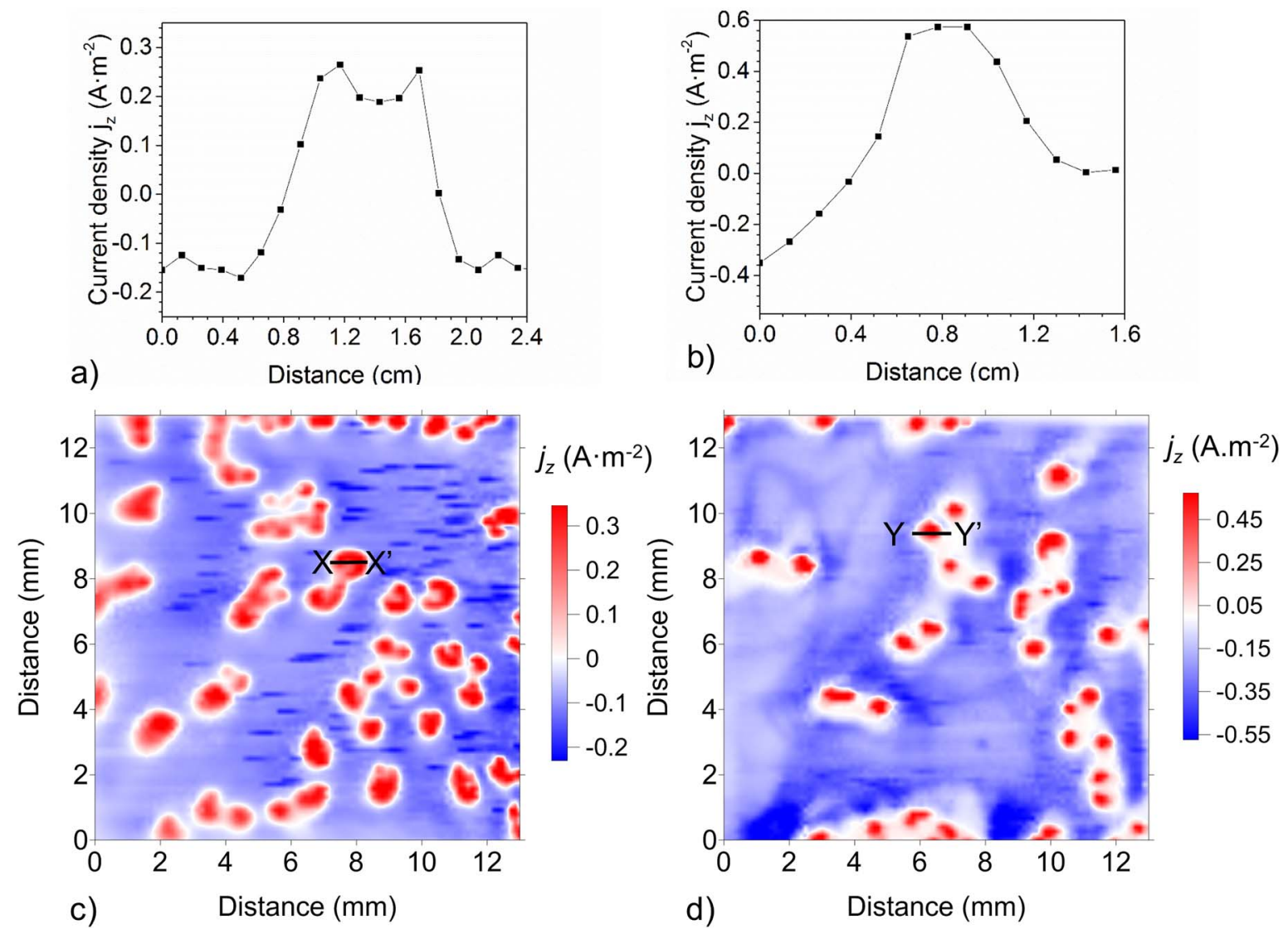

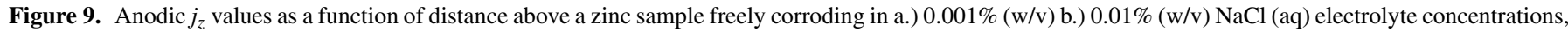
measured along the axes $\mathrm{X}-\mathrm{X}^{\prime}$ (c) and Y-Y' (d) respectively. 

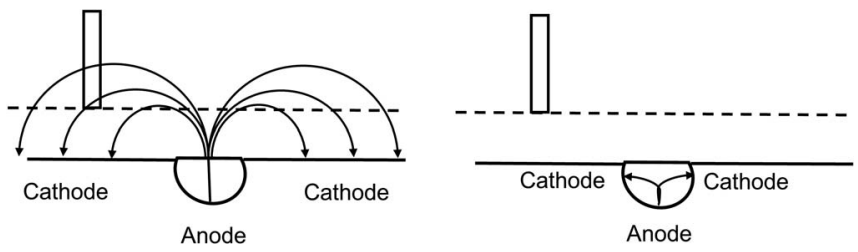

Figure 10. Schematic showing that a.) SVET will be unable to detect any electrochemical activity in the case that ionic flux is consumed within the pit cavity.

immersed in dilute $\mathrm{NaCl}$ electrolyte. However, care was also taken in order to minimize any error associated with the SVET calibration procedure itself. For this reason, calibration was carried out within the tube cell apparatus (Methods section and Figure 1b) which ensured that the SVET probe was, at all times, physically separated from the platinum electrodes used to pass the calibration current by a substantial volume of electrolyte. This in turn minimized the risk that SVET calibration could be influenced by local changes in electrolyte $\mathrm{pH}$ induced by water electrolysis or by any other non-uniform ion distribution stemming from localized electrochemical reactions at the platinum surface. ${ }^{47}$ Given all these safeguards it is likely that the $J_{a(t)}$ values obtained using Equation 3 and shown in Figure 8 are substantially accurate. Nevertheless, wherever possible, quantities calculated from SVET data will be compared with the same quantities calculated by other means.

SVET analysis of pitting kinetics.-In order to be properly detected by SVET, a pit must remain active for a period greater than the time taken for an individual SVET scan (here $\sim 15$ minutes). This implies that all the anodic pits visible in Figures 6 and 7 are stable pits. It may also be seen from Figures 6, 7 and 8 that both the anodic current integral $J_{a(t)}$ and the current emerging from individual pits is substantially constant (time-independent) over the experimental period. On this basis, the time independent value of $J_{a}$ (calculated by numerically integrating all the positive $j_{z}$ values using Equation 3 ) and the pit number density $(n)$, were obtained after allowing the system to stabilize, and used to estimate the mean individual pit current $\left(\overline{i_{\text {pit }}}\right)$ via Equation 9.

$$
\overline{i_{p i t}}=\frac{J_{a}}{n}
$$

Table II shows $J_{a}, n$ and $\overline{i_{p i t}}$ as a function $\overline{i_{p i t}}$ and solution conductivity $K\left(\mathrm{~S} \cdot \mathrm{m}^{-1}\right)$. The SVET determined value of $\overline{i_{p i t}}$ at $[\mathrm{NaCl}]=$ $0.001 \%$ was $(94 \pm 5) \mathrm{nA}$. In an attempt to validate the SVET data obtained the quantities calculated from SVET data were compared with the same quantities calculated by other means. The SVET derived value of $\overline{i_{p i t}}$ is greater the value of $(59 \pm 15) \mathrm{nA}$, previously calculated from the pit depth profile obtained from a different sample after 1 week immersion in the same electrolyte. It should be remembered that the latter value was time averaged and, as such, does not consider how the pit current changes with time. A direct comparison was not possible due to limitations on SVET experimental time periods. Nevertheless, this comparison suggests that SVET is not systematically underestimating pitting currents (as a result of not detecting flux under the plane of scan) to any significant degree.

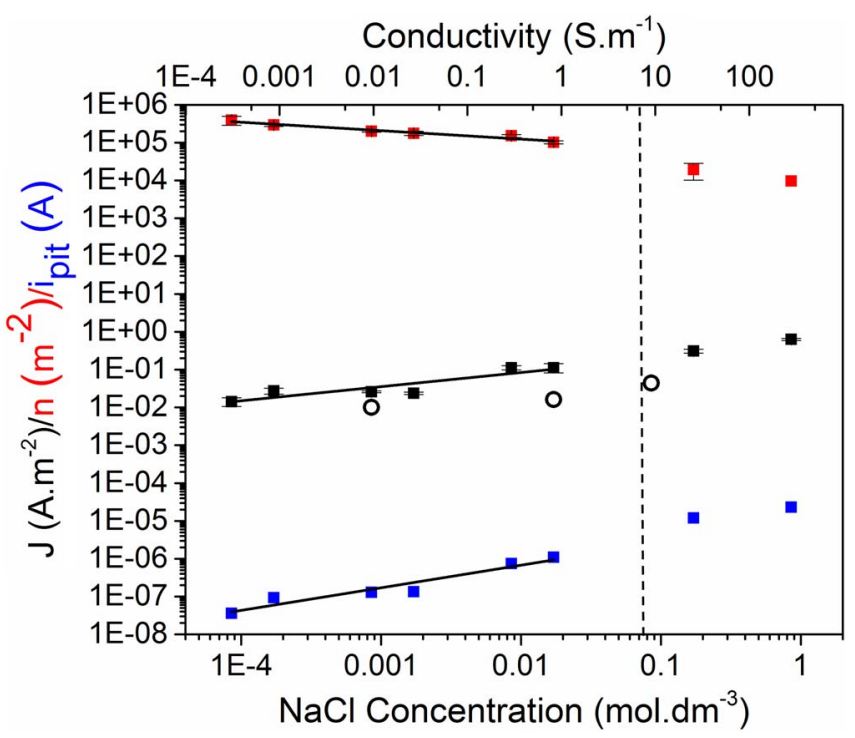

Figure 11. Graph showing the SVET derived total anodic current, number density of pits $(n)$ and current per pit $\left(i_{\text {pit }}\right)$, associated with pure zinc $(\mathrm{Zn})$ samples immersed in $\mathrm{NaCl}(\mathrm{aq})$ electrolytes of varying concentration. Dotted lines are used to separate the data points not used during quantitative analysis. o symbols indicate results published elsewhere. ${ }^{8}$

Figure 11 shows a log-log plot of $J_{a}, n$ and $\overline{i_{p i t}}$ against $[\mathrm{NaCl}]$ and solution conductivity $K\left(\mathrm{~S} \cdot \mathrm{m}^{-1}\right)$. The confidence limits (error bars) given correspond to \pm one standard deviation on the mean of three measurements. The straight lines constructed through the various data between $[\mathrm{NaCl}]=0.001 \%$ and $0.05 \%$ were fitted using least squares linear regression (OriginPro). Due to the deviation from pitting behavior observed in the case of higher $[\mathrm{NaCl}]$, the data obtained when using $[\mathrm{NaCl}]=1 \%$ and $5 \%$ were not fitted and are shown in Figure 11 for illustrative purposes only. The higher $[\mathrm{NaCl}]$ data were not fitted because under these conditions the corrosion of zinc, although localized, does not closely resemble pitting corrosion. Also shown in Figure 11 are pitting corrosion current (area averaged current density) values published previously, from experiments using a two-compartment cell (indicated by hollow circle symbols $\circ$ ). ${ }^{8}$ The corrosion current values reported in that work were estimated by measuring the current passing between a borate buffer containing compartment (non-pitting) the other (the pitting compartment) using a zero resistance ammeter. The pitting corrosion current density was defined as (total current flowing in the circuit)/(total area of the electrode undergoing attack). ${ }^{8} \mathrm{~A}$ comparison of the two-compartment cell data with the SVET-derived $J_{a}$ data suggests that SVET is efficiently detecting pitting currents on zinc and that the use of Equation 3 is not resulting in any significant systematic underestimation of $J_{a}$.

The following empirical relationships were obtained from the gradients of the various lines in Figure 11;

$$
\log J_{a}=A+a \log [\mathrm{NaCl}]
$$

$\log n=B+b \log [\mathrm{NaCl}]$

\begin{tabular}{|c|c|c|c|c|c|c|}
\hline 0.0005 & 0.00085 & $394000 \pm 74000$ & $36 \pm 8$ & 1.63 & & \\
\hline 0.001 & 0.0017 & $291000 \pm 16000$ & $94 \pm 5$ & 1.90 & $0.40 \pm 0.15$ & 13.1 \\
\hline 0.005 & 0.0085 & $199000 \pm 6000$ & $130 \pm 4$ & 2.30 & & \\
\hline 0.01 & 0.017 & $176000 \pm 16000$ & $135 \pm 13$ & 2.44 & $0.15 \pm 0.03$ & 7.4 \\
\hline 0.05 & 0.085 & $151000 \pm 10000$ & $746 \pm 59$ & 2.64 & & \\
\hline
\end{tabular}


Table III. Values of the constants given in the empirical relationships obtained using Figure 11.

\begin{tabular}{cccc} 
Quantity & Intercept & Slope & $\mathrm{R}^{2}$ \\
\hline$J\left(A \cdot m^{-2}\right)$ & $A=(-0.329 \pm 0.184) A \cdot m^{-2}$ & $a=(0.374 \pm 0.061) \frac{A \cdot L}{\mathrm{~m}^{2} \cdot m o l}$ & 0.81 \\
$n\left(m^{-2}\right)$ & $B=(4.647 \pm 0.048) m^{-2}$ & $b=(-0.223 \pm 0.016) \frac{L}{\mathrm{~m}^{2} \mathrm{~mol}}$ & 0.96 \\
$\overline{i_{p i t}(A)}$ & $C=(-4.976 \pm 0.170) \mathrm{A}$ & $c=(0.597 \pm 0.056) \frac{\mathrm{A} \cdot \mathrm{L}}{\mathrm{mol}}$ & 0.93
\end{tabular}

$$
\log \overline{i_{p i t}}=C+c \log [\mathrm{NaCl}]
$$

where $A, B, C, a, b$ and $c$ are constants given in Table III. $50 \%$ confidence intervals are shown thoughout.

The finding that the experimentally determined $\log \overline{i_{p i t}} /$ $\log [\mathrm{NaCl}]$ slope is $\sim 0.6$ (given by Equation 10 and shown by Figure 11 ) implies that the dependence of $\overline{i_{p i t}}$ on $K$ has an order significantly less than one. This would seem to be inconsistent with a straightforward ohmic limitation of $\overline{i_{p i t}}$ and might be taken to imply a degree of either activation control or some other form of mass transport control. However, it should be borne in mind that the local corrosion picture "relaxes" to accommodate changes in $K$. That is to say, as $[\mathrm{NaCl}]$ and $K$ decrease so $n$ increases. The increase in $n$ implies an effective reduction in the typical pathlength that ionic current flux must traverse in passing from the anodic pit to the surrounding cathodic metal surface. This "relaxation" would therefore tend to oppose the effect of decreasing solution conductivity in decreasing $\overline{i_{p i t}}$ and so reduce the order of dependence between $\overline{i_{\text {pit }}}$ and $[\mathrm{NaCl}]$. Thus the experimentally determined $\log \overline{i_{\text {pit }}} / \log [\mathrm{NaCl}]$ slope of $\sim 0.6$ does not necessarily preclude a high degree of ohmic control in the overall rate of pitting corrosion and it would seem very probable that this indeed does become the case as $[\mathrm{NaCl}]$ tends toward zero. An exactly similar argument can be applied to the $\log \mathrm{J}_{a} / \log [\mathrm{NaCl}]$ slope of $\sim 0.4$.

On the face of it, the finding in Table II and Figure 1 that $n$ decreases with increasing $[\mathrm{NaCl}]$ would appear paradoxical, implying as it does, that conditions are somehow becoming "less aggressive" at chloride ion concentration increases. However, it should be borne in mind that zinc is so weakly passive that conditions are adequately aggressive to produce a high frequency of film breakdown (and transient pitting) over the entire experimental range of $[\mathrm{NaCl}]$. What determines the value of $n$ is whether or not pits make the transition to stable pitting and this, in turn, is influenced by the physical range (length scale) over which pits interact through the external electrolyte. It is this effect which is the subject of the following analysis.

Pit-pit interaction and the role of electrolyte conductivity.-The chemistry of the electrolyte in the vicinity of an existing stable pit can reasonably be expected to play a role in determining the probability that fresh pits will stabilize in that vicinity. In the case of materials for which metal cation hydrolysis is associated with an acidic pKa value, the aggressive (acidic) environment forming near a pit will tend to favor the stabilization of further pits. A real time microscopic in situ visualization technique has previously been used to show autocatalytic growth of metstable pits on stainless steel, ${ }^{50,51}$ an effect which was believed to occur as a result of a weakening of the film around an existing active pit over a distance $\leq$ diffusion length of aggressive ions. ${ }^{52}$ Conversely, $\mathrm{OH}^{-}$ions produced through the ORR, will tend to offset aggressive conditions around a stable pit by alkalizing the metal surface and keep it passive.

As has been argued earlier, the first hydrolysis coefficient $\left(\mathrm{pKa}_{1}\right)$ associated with $\mathrm{Zn}^{2+}$ hexaquocation (Equation 2), is $9^{21}$ and hydrolytic acidification is therefore likely to be limited in the case of zinc. Consequently, it is surface alkalization though the ORR which is likely to have the predominant influence on the stabilization (or not) of neighboring pits. Under these circumstances, it is the distance over which cathodic activity extends away from an existing stable pit which will determined the range of pit-pit interaction. In the case that the ORR is suppressed by an ohmic overpotential (for example in dilute electrolytes) the $\mathrm{pH}$ in those regions of the metal surface where cathodic current densities are diminished will tend to remain low and surface repassivation will be less likely to occur.

The ohmic potential drop associated with current emerging from an existing stable pit will increase with distance and the stabilization of new pits therefore becomes more likely at greater distance from an existing stable pit. The value of $b$ in Equation 11 is $-0.200 \pm$ 0.032 , implying that the number concentration of pits, and hence pit-pit distance depends on $[\mathrm{NaCl}]$ but in a complex (non-linear) fashion. To better understand the relationship between pit-pit spacing and $[\mathrm{NaCl}]$ we need to understand the relationship between ohmic potential drop in the external solution, $[\mathrm{NaCl}]$ and the radial distance away from an existing active pit. In order to answer this question exactly it would be necessary to solve the Laplace equation describing the pit (anode)-surrounding substrate (cathode) current-voltage problem. Such a solution would require an accurate definition of the boundary conditions and even then would, most probably, only be soluble by numerical means. Consequently, we have used a simplified geometric analysis based on a calculation of the radial dependence of electrical resistance exhibited by a hemispherical shell of electrolyte above the pit at the metal substrate-solution interface. Such an approach is obviously not completely accurate, as it assumes an isotropic radiation of current flux from the pit into solution. Nevertheless, it has the advantage of yielding a relatively simple expression linking $\overline{i_{\text {pit }}}$ and radial distance to ohmic potential drop. Here we use this analysis to test the hypothesis that pit-pit interaction and pit-pit spacing might be mediated by ohmic potential gradients in the solution external to the pits.

We begin by using the Ohm's law expression given in Equation 13.

$$
\Delta V_{\text {max }}=\overline{i_{\text {pit }}} R
$$

where $\Delta V_{\max }$ is the maximum permissible ohmic potential drop in the external electrolyte if cathodic current density is to be maintained above the critical value required to suppress the stabilization of neighboring pits. The sample surface is assumed to be split into a number of circular domains, each of which have a pit at the center. The domain radius is defined as $\frac{L}{2}$ and the pit-pit spacing is therefore given by $L$. The origin of the ohmic drop, $\Delta V$, and the relationship between $\Delta V_{\max }$ and $L$ is shown schematically in Figure 12. The schematic is a visual representation of the previously reported observation that anode-cathode spacing is small in the case of low ionic conductivity electrolytes as acid generated at the anodes is quickly neutralized by the base generated at the cathodes before it can spread further. ${ }^{4}$ At distances $r<\frac{L}{2}$ the pit will effectively suppress the stabilization of other transient pitting events (by cathodically polarizing the sample surface). Conversely, at $r>\frac{L}{2}$ the pit will have no influence on the stabilization of other transient pitting events and new stable pits will evolve (Figure 12a).

The radial solution resistance $(R)$ exhibited by a hemispherical shell of electrolyte above a pit would be given by Equation 14 where $K$ is conductivity and $r_{l}$ and $r_{2}$ are the pit radius and $L / 2$ respectively. In the case that $V_{\max }$ is constant, Equation 15 can be written.

$$
R=\frac{1}{2 \pi K}\left(\frac{1}{r_{1}}-\frac{1}{r_{2}}\right)
$$




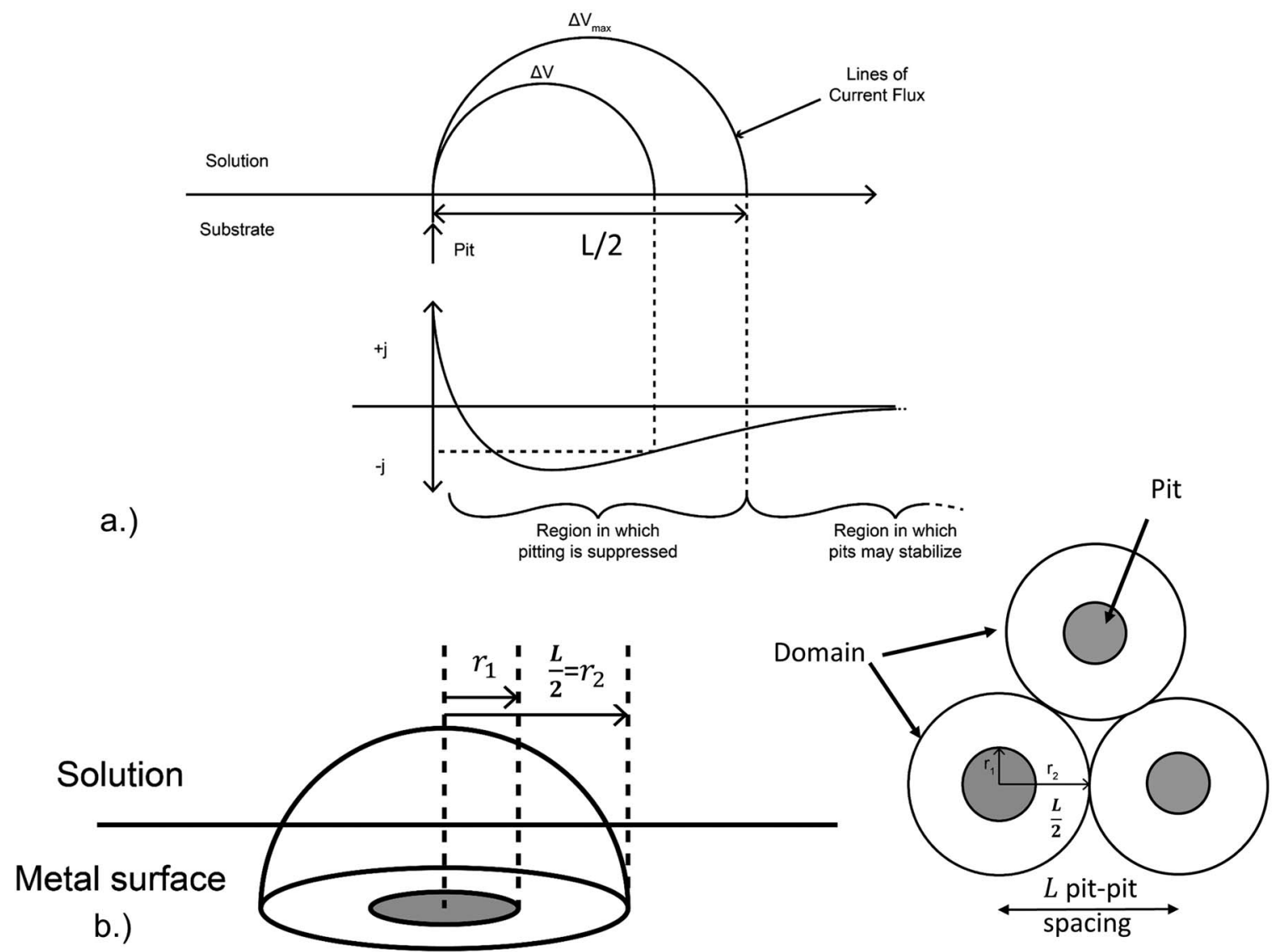

Figure 12. Schematic of a.) the ohmic potential gradients developing in the external electrolyte mean that $i_{\text {pit }}$ will give rise to a corresponding ohmic overpotential $\Delta V$. The distance over which $i_{\text {pit }}$ can be maintained for an individual pit is given by $\frac{L}{2}$ and b.) a cylinder (or disk) of solution co-axial with the pit, and normal to the sample surface which is used as a simple geometric representation of the ohmic potential drops in the solution external to the pit.

$$
V_{\text {max }}=\frac{\overline{i_{p i t}}}{2 \pi K}\left(\frac{1}{r_{p i t}}-\frac{1}{L / 2}\right)
$$

If it is assumed that the sample surface area $A$ is covered in a large number of domains $(n)$ of equal dimension, and radius $\frac{L}{2}$ then

$$
\begin{gathered}
\frac{A}{n}=\frac{\pi L^{2}}{4} \\
\frac{L}{2} \propto \frac{1}{\sqrt{\pi n}} \cdot \frac{\pi}{2 \sqrt{3}}
\end{gathered}
$$

where $\frac{\pi}{2 \sqrt{3}}$ is the packing factor of circles in a plane. ${ }^{53,54}$ Equation 15 can then be rearranged to give Equation 18

$$
\frac{K}{\overline{i_{p i t}}}=\frac{1}{2 \pi V_{\max }}\left(\frac{1}{r_{p i t}}-\sqrt{\pi n}\right)
$$

Values of $V_{\max }$ were calculated for each [ $\left.\mathrm{NaCl}\right]$ using Equation 18. Values of $r_{p i t}$ were obtained from optical images (Figure 3) and SVET surface maps (Figure 6) and values of $L$ were calculated using Equation 17. $V_{\max }$ values of $13.1 \mathrm{mV}, 7.4 \mathrm{mV}$ and $6.2 \mathrm{mV}$ were obtained for $0.001 \%, 0.01 \%$ and $0.1 \%$ respectively. As shown by Equation 4 to Equation 6, the ORR can take place via a combination of 2 and 4 electron pathways. However, it has been shown that on oxide covered zinc (near the OCP) ORR occurs primarily via the 2 electron pathway (Equation 5), for which the relevant Tafel slope has been shown to be $58 \mathrm{mV}$ per decade. ${ }^{42}$ The change in ORR current density $\Delta i$ which occurs as a result of the ohmic reduction in the overpotential driving electron transfer is given by Equation 19.

$$
\Delta \log i=-\frac{V_{\max }}{58}
$$

The $\mathrm{O}_{2}$ cathodic current density values are reduced to $60 \%, 75 \%$ and $78 \%$ of their original value, respectively. These relatively modest variations in cathodic current density are consistent with the failure to observe, in Figures 6 and 7, any strongly marked localization of cathodic currents in the region between corrosion pits. Furthermore, they suggest that pit-pit interaction on zinc can be mediated as a consequence of ohmic potential drops in the external electrolyte influencing the probability of pit stabilization through relatively subtle ohmic modulations of ORR activity.

\section{Conclusions}

A systematic scanning vibrating electrode technique study, examining the pitting corrosion of unpolarized pure $\mathrm{Zn}$ in varying concentrations of $\mathrm{NaCl}(\mathrm{aq})$, has been completed and shown that;

- total anodic corrosion current density varies with approximately the square root of $[\mathrm{NaCl}]$;

- the number density of pits (pits per unit area) decreases with increasing $[\mathrm{NaCl}]$;

- the dependence of individual pit current varies with approximately the square root of $[\mathrm{NaCl}]$;

- the dependence of pit number density upon $[\mathrm{NaCl}]$ is consistent with a through-solution pit-pit interaction on zinc occurring in dilute electrolytes. This interaction is mediated through ohmic potential drops in electrolyte external to an existing pit, which influences the 
probability of new pit stabilization by modulating of ORR activity on the surrounding metal surface.

A simple geometric analysis, based on a calculation of the radial dependence of electrical resistance exhibited by a hemispherical shell of electrolyte concentric with the pit, was used to better understand the relationship between ohmic potential drop in the external solution, solution conductivity, and the radial distance away from an existing active pit.

Empirical SVET data was used to calculate values of between 6.2 and $13 \mathrm{mV}$ for the maximum permissible ohmic drop in the external solution, above which, the cathodic current density on the surrounding metal surface will fall below a critical value required to suppress pit stabilization. The cathodic oxygen reduction current falls to approximately $60-78 \%$ of its original value meaning that, in the case of dilute electrolytes, the stabilization of new pits on oxide covered zinc is only likely to take place outside a certain radial distance from any existing pit.

\section{Acknowledgments}

The authors thank EPSRC for funding via Industrial CASE award 08000751 and Tata Steel.

\section{ORCID}

N. Wint () https://orcid.org/0000-0002-9229-5728

\section{References}

1. M. G. Alvarez and J. R. Galvele, Corrosion, 32, 285 (1976).

2. U. R. Evans and D. E. Davies, Corrosion, 8, 165 (1952).

3. A. D. Keitelman, S. M. Gravano, and J. R. Galvele, Corrosion Science, 24, 535 (1984).

4. X. G. Zhang, Corrosion and Electrochemistry of Zinc, Springer Science \& Business Media (1996).

5. U. R. Evans, Chemistry and Industry, 1291 (1956).

6. W. Miao, I. S. Cole, A. K. Neufeld, and S. Furman, J. Electrochem. Soc., 154, C7 (2007).

7. D. Nakhaie and E. Asselin, J. Electrochem. Soc., 164, C758 (2017).

8. E. E. Abd El Aal, Corrosion Science, 46, 37 (2004).

9. F. H. Assaf, S. S. Abd El-Rehiem, and A. M. Zaky, Materials Chemistry and Physics, 58, 58 (1999).

10. E. E. Abd El Aal, Corrosion Science, 44, 2041 (2002).

11. D. E. Davies and M. M. Lotlikar, British Corrosion Journal, 1, 149 (1966).

12. S. M. Abd El Haleem, British Corrosion Journal, 11, 215 (1976).

13. T. P. Hoar, D. C. Mears, and G. P. Rothwell, Corrosion Science, 5, 279 (1965).

14. P. Marcus and J.-M. Herbelin, Corrosion Science, 34, 1123 (1993).

15. N. Sato, Electrochimica Acta, 16, 1683 (1971).
16. J. A. Richardson and G. C. Wood, Corrosion Science, 10, 313 (1970).

17. H. H. Uhlig, J. Electrochem. Soc., 97, 215C (1950).

18. J. R. Galvele, J. Electrochem. Soc., 123, 464 (1976).

19. P. C. Pistorius and G. T. Burstein, Philosophical Transactions of The Royal Society A: Mathematical, Physical and Engineering Sciences, 341, 531 (1992).

20. G. S. Frankel, J. Electrochem. Soc., 145, 2186 (1998).

21. C. F. Baes and R. E. Mesmer, The Hydrolysis of Cations, Wiley, New York (1976).

22. D. E. Irish, B. McCarroll, and T. F. Young, The Journal of Chemical Physics. 39, 3426 (1963)

23. T. Yamaguchi, S. Hayashi, and H. Ohtaki, The Journal of Physical Chemistry. 93, 2620 (1989)

24. C. C. Pye, C. R Corbeil, and W. W. Rudolph, Physical Chemistry Chemical Physics. 8, 5428 (2006).

25. I. D. Brown, The Chemical Bond in Inorganic Chemisty: The Bond Valence Model, Oxford University Press (2006).

26. T. T. Lunt, J. R. Scully, V. Brusamarello, A. S. Mikhailov, and J. L. Hudson, J. Electrochem. Soc., 149, B163 (2002).

27. L. Organ, J. R. Scully, A. S. Mikhailov, and J. L. Hudson, Electrochimica Acta, 51, 225 (2005).

28. L. Organ, Y. Tiwary, J. R. Scully, A. S. Mikhailov, and J. L. Hudson, Electrochimica Acta, 52, 6784 (2007).

29. J. Newman, J. Electrochem. Soc., 113, 501 (1966).

30. N. J. Laycock and R. C. Newman, Corrosion Science, 39, 1771 (1997).

31. G. Butler, H. C. K. Ison, and A. D. Mercer, British Corrosion Journal, 6, 31 (1971).

32. I. L Rosenfield and I. S. Danilov, Corrosion Science, 7, 129 (1967).

33. M. Pourbaix, Atlas of Electrochemical Equilibria in Aqueous Solutions, Pergamon Press (1966).

34. S. Thomas, N. Birbilis, M. S. Venkatraman, and I. S. Cole, Corrosion Science, 68 , 015009 (2012).

35. H. S. Isaacs and G. Kissel, J. Electrochem. Soc., 119, 1628 (1972).

36. H. S. Isaacs, J. Electrochem. Soc., 138, 722 (1991).

37. G. Williams and H. N. McMurray, J. Electrochem. Soc., 155, C340 (2008).

38. S. Bohm, H. N. McMurray, S. M. Powell, and D. A. Worsley, Electrochmica Acta, 45, 2165 (2000).

39. D. Worsley, H. N. McMurray, and A. Belghazi, Chem. Commun., 24, 2369 (1997).

40. S. M. Powell and D. A. Worsley, British Corrosion Journal, 36, 42 (2001).

41. G. Williams, H. N. McMurray, and R. Grace, Electrochimica Acta, 55, 7824 (2010).

42. H. Dafydd, D. A. Worsley, and H. N. McMurray, Corrosion Science, 47, 3006 (2005).

43. G. W. C. Kaye and T. H. Laby, Tables of Physical and Chemical Constants, p. 219 , Longman, London (1986).

44. G. Williams and H. N. McMurray, Corrosion, 62, 231 (2006).

45. G. Williams, A. J. Coleman, and H. N. McMurray, Electrochimica Acta, 55, 5947 (2010).

46. M. Hayase, T. Hatsuzawa, and A. Fukuiumi, Journal of Electroanalytical Electrochemistry, 537, 173 (2002).

47. J. H. Sullivan, H. N. McMurray, D. J. Penney, and D. A. Worsley, ECS Transactions. 1, 413 (2006)

48. C. J. T. de Grotthuss, Ann. Chim. Phys., LVIII, 54 (1806).

49. V. K. Henry, CRC handbook of thermophysical and thermochemical data, CRC Press Inc., Boca Raton (1994).

50. A. S. Mikhailov, J. R. Scully, and J. L. Hudson, Surface Science, 603, 1912 (2009).

51. C. Punckt, M. Bölscher, H. H. Rotermund, A. S. Mikhailov, L. Organ, N. Budiansky, and J. R. Scully, Science, 305, 1133 (2004).

52. G. S. Frankel, L. Stockert, F. Hunkeler, and H. Boehni, Corrosion, 43, 429 (1987).

53. A. Thue, Norske Vid. Selsk. Skr. No. 1, 1 (1910).

54. L. F. Toth, Math. Z., 48, 676 (1943). 